\title{
Do parents' and children's perceptions of the community environment affect children's physical activity levels?
}

Yu DONG, Harbin Institute of Technology/Key Laboratory of Cold Region Urban and Rural Human Settlement Environment Science and Technology, Ministry of Industry and Information Technology, China

Fengjing LI, Harbin Institute of Technology/Institute for China Sustainable Urbanization, Tsinghua

University, China /Key Laboratory of Cold Region Urban and Rural Human Settlement Environment Science and Technology, Ministry of Industry and Information Technology

Wei DONG, Harbin Institute of Technology/Key Laboratory of Cold Region Urban and Rural Human Settlement Environment Science and Technology, Ministry of Industry and Information Technology, China

Erli ZENG, Southwest University of Science and Technology/ Harbin Institute of Technology/Key Laboratory of Cold Region Urban and Rural Human Settlement Environment Science and Technology, Ministry of Industry and Information Technology, China

\begin{abstract}
Inadequate physical activity among Chinese children may be a potential behavioral contributor to their health problems such as reduced fitness and obesity, especially in the context of worldwide childhood overweight tendency and progressively increase obesity rates. In recent years, many studies have shown that parents' and children's perceptions of their community environment are critical to children's physical activity levels. In this context, this study empirically demonstrated the effect of perceptions of the community environment on children's physical activity levels by using linear regression analysis and structural equation modeling with children aged 9-12 years in Bei'an, China. The findings suggested that both parents' and children's perceptions of the community environment influence children's physical activity and that the total effect of both is essentially the same. However, there were differences in the level of impact of specific perceived factors. Parents' and children's perceived characteristics of community activity places and facilities had the most significant effect on children's physical activity levels. The findings have important implications for building child-friendly community environments and promoting children's physical activity levels.
\end{abstract}

\section{Keywords}

Environmental perceptions, Total effect, School-age children, Activity places and facilities, Sense of safety

\section{Introduction and review}

Chinese guidelines on physical activity for children recommend that children engage in moderate-tovigorous physical activity for more than 60 minutes per day, the same standard recommended in most countries in the world. According to the 2018 Report Card on Physical Activity for Children and Youth in several countries, the attainment rates for children in Canada, the United States, Germany, and Mexico were $35 \%, 24 \%, 20 \%$, and $17 \%$, respectively. Yet, only $13.1 \%$ of children aged $9-17$ in China met the recommended standards. Regular physical activity has been shown to reduce obesity, cardiovascular disease, stroke, and osteoarthritis(Ryu et al.,2019; Ward et al.,2019; Weaver et al.,2017). The current lack of physical activity among Chinese children may be essential causative factor for childhood obesity and health problems. 
A GPS study to track children's behavior showed that $63 \%$ of children's physical activity was performed within the neighborhood(Jones et al.,2009). Besides the community's built-up environment, the perceptions of the community environment also influence children's physical activity, including the perceptions of parents and children(Trapp et al.,2012;Davison and Lawson,2006).

Their parents influence children's behaviors throughout childhood(Ginsburg et al.,2007). Parental perceptions of the neighborhood environment determine children's sedentary behavior, physical activity, and travel habits(Tappe et al.,2013). Parents of children who engage in physical activity from time to time are statistically more likely to agree on the importance of neighborhood aesthetics, neighborhood satisfaction, active play areas and facilities, walkability, and safety than those who rarely exercise(Carson et al.,2010;Roberts et al.,2016;Roemmich et al.,2006; Veugelers et al.,2008;Weir,Etelson and Brand,2006). Research related to children's perceptions empirically demonstrates that the number of exercise facilities, the density of road crossings, smoothness of walking paths, and children's sense of safety are critical environmental factors that influence children's physical activity behavior(Carroll-Scott et al.,2013;Timperio et al.,2004). Moreover, children pay more attention to the interesting aspect of the community environment than adults(Gouteux and Spelke, 2001;Yamashita,2002) .

\section{Method Overview}

\subsection{Introduction of the study area}

The study area of this research is Bei'an City, Heilongjiang Province, China, with an urban area of 8 square kilometers and population of 205,000. Currently, many rural people in Bei'an are moving to the town. The town is expanding rapidly, which is classified as a pilot area for new urbanization by the government because these characteristics align with the development features of new urbanization in China. Research on the impact of children's physical activity in Bei'an City can better guide the construction of urban community environments, reflecting spatial justice in the process of new urbanization.In this study, based on the characteristics of elementary school location distribution and urban built environment, students in grades 3-5 from seven elementary schools in the main urban area of Bei'an City were selected as the study object, and the specific distribution of these schools is shown in Figure 1. 


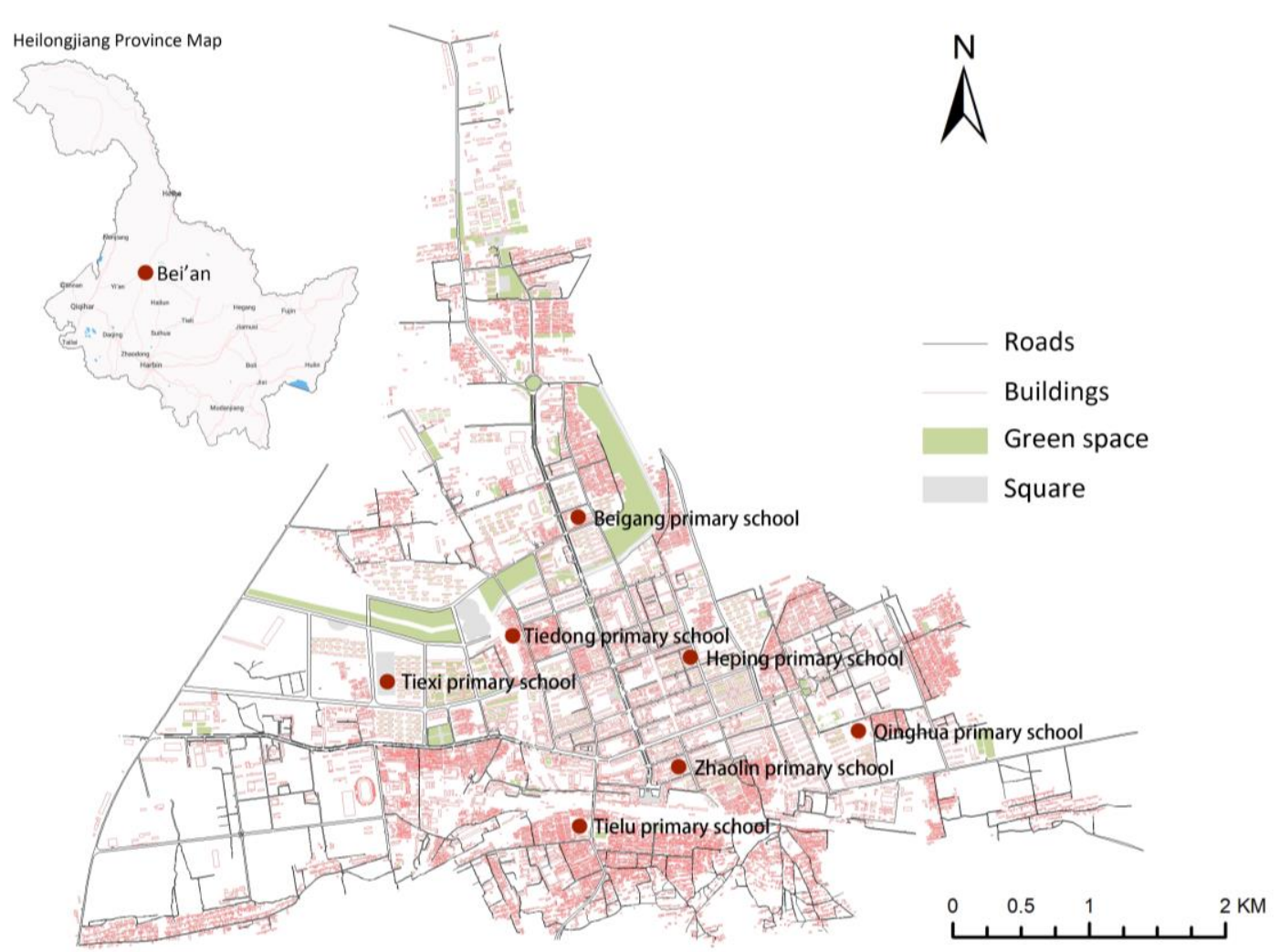

Figure 1. The distribution of seven selected primary schools in Bei'an City

\subsection{Research design}

The study used a questionnaire that included four sections: children and family information, parents' perceptions of community environment, children's perceptions of community environment, and children's physical activity levels. Since studies have confirmed that parental proxy reports of children's physical activity are superior to child self-reports(Sithole and Veugelers,2008), the questions on child perceptions were answered by themselves, and their parents responded to the other sections.

The children and family information includes children's age, gender, height and weight, parents' education, occupation, annual household income, etc. Parents' perceived environment's questions involve 14 indicators in 4 aspects: community satisfaction and atmosphere, landscape environment, activity place and facilities, and safety. The questions on children's perceived environment involve six indicators in 4 aspects: attachment, safety, playability, and fun. They all set the answers in the form of a 5 -point scale (1=perceptions very bad, $5=$ =erceptions very good).

The study selected the revised CLASS-C (The Children's Leisure Activities Study Survey-Chinese Version) scale to quantify children's physical activity levels, containing a total of 25 physical activity items. The response options were $0 \mathrm{~min}, 0-30 \mathrm{~min}, 30-60 \mathrm{~min}, 1 \mathrm{~h}-2 \mathrm{~h}, 2 \mathrm{~h}-4 \mathrm{~h}, 4 \mathrm{~h}$ or more. Used the midpoint of the response options to estimate the duration of children's physical activity and queried the metabolic equivalent (MET) values corresponding to the 25 physical activity items in the physical activity compendium (Ainsworth et al.,2000). The energy consumption values were quantified using the following equation to measure the children's physical activity levels:

Energy consumption for physical activity $=($ MET $\times 3.5 \times$ Weight $\times$ Time $) / 200$ 


\subsection{Study data collection}

The study used a web-based questionnaire distributed to parents (children in grade 3-5) in the study area on the same day in June 2020. One thousand twelve households living in urban areas completed this web-based questionnaire, with 920 valid questionnaires (91\%). The Cronbach's alpha was more significant than 0.7, and the KMO (Kaiser-Meyer-Olkin) was more effective than $0.8(p<0.001)$, suggesting that the reliability test results of the questionnaire were good.

The children and family information of the sample is shown in Table 1. The sample size of male children was 472 , accounting for $51.31 \%$, and female children accounted for $48.69 \%$. The gender ratio was similar to the overall proportional characteristics of children in grades 3-5 in the study area. Most parents(both fathers and mothers)were less educated with diploma lower than high school. The majority of the interviewees were full-time and temporary workers, and followed by a high proportion of farmers and self-employed, which is similar to most small towns in Northeast China, showing that the sample is representative.

Table 1. The primary information of the sample

\begin{tabular}{|c|c|c|c|c|c|c|c|}
\hline Variables & Categories & $\begin{array}{c}\text { Numbe } \\
r\end{array}$ & Percent & Variables & Categories & Number & Percent \\
\hline \multirow{2}{*}{$\begin{array}{l}\text { Child } \\
\text { gender }\end{array}$} & Male & 472 & $51.31 \%$ & \multirow{4}{*}{ Child Age } & 9 & 90 & $9.78 \%$ \\
\hline & Female & 448 & $48.69 \%$ & & 10 & 271 & $29.46 \%$ \\
\hline \multirow{2}{*}{ Only child } & Yes & 674 & $73.26 \%$ & & 11 & 333 & $36.19 \%$ \\
\hline & No & 246 & $26.74 \%$ & & 12 & 226 & $24.57 \%$ \\
\hline \multirow{5}{*}{$\begin{array}{l}\text { Father's } \\
\text { Education }\end{array}$} & $\begin{array}{l}\text { Elementary school } \\
\text { or lower }\end{array}$ & 65 & $7.07 \%$ & \multirow{5}{*}{$\begin{array}{l}\text { Mother's } \\
\text { Education }\end{array}$} & $\begin{array}{l}\text { Elementary school } \\
\text { or lower }\end{array}$ & 48 & $5.22 \%$ \\
\hline & Middle school & 411 & $44.67 \%$ & & Middle school & 444 & $48.26 \%$ \\
\hline & $\begin{array}{l}\text { High (or technical) } \\
\text { school diploma }\end{array}$ & 199 & $21.63 \%$ & & $\begin{array}{l}\text { High (or technical) } \\
\text { school diploma }\end{array}$ & 178 & $19.35 \%$ \\
\hline & Associate degree & 13 & $14.57 \%$ & & Associate degree & 124 & $13.48 \%$ \\
\hline & $\begin{array}{l}\text { Bachelor or } \\
\text { graduate degree }\end{array}$ & 112 & $12.18 \%$ & & $\begin{array}{l}\text { Bachelor or } \\
\text { graduate degree }\end{array}$ & 126 & $13.69 \%$ \\
\hline \multirow{6}{*}{$\begin{array}{l}\text { Father's } \\
\text { Occupation }\end{array}$} & Fulltime worker & 285 & $30.98 \%$ & \multirow{6}{*}{$\begin{array}{l}\text { Mother's } \\
\text { Occupation }\end{array}$} & Fulltime worker & 270 & $29.35 \%$ \\
\hline & Self-employed & 164 & $17.83 \%$ & & Self-employed & 153 & $16.63 \%$ \\
\hline & Farmer & 162 & $17.60 \%$ & & Farmer & 139 & $15.11 \%$ \\
\hline & Temporary worker & 277 & $30.11 \%$ & & Temporary worker & 252 & $27.39 \%$ \\
\hline & Unemployed & 25 & $2.72 \%$ & & Unemployed & 104 & $11.30 \%$ \\
\hline & Retired & 7 & $0.76 \%$ & & Retired & 2 & $0.22 \%$ \\
\hline \multirow{6}{*}{$\begin{array}{l}\text { Annual } \\
\text { household } \\
\text { income }\end{array}$} & Below 10,000 & 121 & $13.15 \%$ & \multirow{4}{*}{$\begin{array}{l}\text { Household } \\
\text { main trip } \\
\text { mode }\end{array}$} & Walking & 472 & $51.30 \%$ \\
\hline & $10,000-30,000$ & 274 & $29.78 \%$ & & Public transit & 115 & $12.50 \%$ \\
\hline & $30,000-80,000$ & 329 & $35.76 \%$ & & Taxi & 31 & $3.37 \%$ \\
\hline & $80,000-120,000$ & 131 & $14.24 \%$ & & Private car & 302 & $32.83 \%$ \\
\hline & $120,000-200,000$ & 48 & $5.22 \%$ & & & & \\
\hline & 200,000 or more & 17 & $1.85 \%$ & & & & \\
\hline
\end{tabular}

\subsection{Analysis methods}

First, two linear regression equations were established with parents' perceived environmental and children's perceived environmental characteristics as independent variables, and children's physical activity levels as dependent variables to analyze the effects of parental and child perceptions factors on 
children's physical activity levels. Second, structural equation modeling (SEM) was developed through AMOS software to investigate the impact of several dimensions of parents' perceived environmental characteristics on children's physical activity levels. Finally, further explored the total effect of parental perceptual features and child perceptual characteristics on children's physical activity levels through SEM.

\section{Results}

\subsection{The effects of parents' perceptions}

Table 2 shows that the factors with significant effects (Sig. value $<0.05$ ) on children's physical activity levels by the parental perceptions of environmental characteristics are, in order of the magnitude of their impact on children's physical activity levels: number of sports fields, number of places to play, number of play facilities, number of sports facilities, walkability, traffic safety, and community attachment.

Table 2. Results of the effects of parental environmental perceptions factors

\begin{tabular}{|c|c|c|c|c|}
\hline & $\begin{array}{c}\text { Non-standardized } \\
\text { coefficient }\end{array}$ & $\begin{array}{l}\text { Standardized } \\
\text { coefficient }\end{array}$ & $\mathrm{t}$ & Sig \\
\hline Community likeability & 78.802 & 0.081 & 1.714 & 0.087 \\
\hline Community satisfaction & 53.987 & 0.058 & 1.228 & 0.220 \\
\hline Community familiarity & 11.304 & 0.010 & 0.331 & 0.741 \\
\hline Community attachment & 88.596 & 0.088 & 2.191 & 0.029 \\
\hline Number of sports fields & 263.264 & 0.171 & 6.157 & 0.000 \\
\hline Number of places to play & 195.011 & 0.146 & 5.141 & 0.000 \\
\hline Number of sports facilities & 206.147 & 0.117 & 3.823 & 0.000 \\
\hline Number of play facilities & 186.285 & 0.132 & 4.210 & 0.000 \\
\hline Street sanitation & 37.087 & 0.029 & 0.854 & 0.393 \\
\hline Greenery & 4.849 & 0.004 & 0.125 & 0.901 \\
\hline Number of sidewalks & 61.695 & 0.059 & 1.931 & 0.054 \\
\hline Walkability & 105.320 & 0.110 & 2.829 & 0.005 \\
\hline Traffic safety & 104.532 & 0.107 & 2.696 & 0.007 \\
\hline Fear of accidents & 37.978 & 0.037 & 1.252 & 0.211 \\
\hline
\end{tabular}

Notes: $R=0.737, R^{2}=0.542$, adjust $R^{2}=0.535$

Figure 2 shows the effect of several dimensions of parental perceptions of environmental characteristics on children's physical activity levels. M.I. was used to judge the model fitness and to make corrections. The model parameter indicators CMIN/DF, GFI, AGFI, CFI, and RMSEA were $4.262(>3), 0.951$ (>0.90), 0.927 (>0.90), 0.967 (>0.90), and 0.060 (<0.08 reasonable) in order, which all reached the appropriate standard, indicating that the model was acceptable, its fit was good, and its structure had statistical significance. As shown in Table 3, the overall significant $p$-values for the effects of parental environmental perceptions of community satisfaction and atmosphere, activity place and facilities, landscape environment, and safety on children's physical activity were less than 0.05 . The C.R. values were all greater than 1.96, indicating that the effects of all four dimensions were significant. The results of SEM revealed that the dimensions of parents' perceived environment had the following effects on children's physical activity levels in order of magnitude: activity place and facilities, safety, community satisfaction and atmosphere, and landscape environment. 


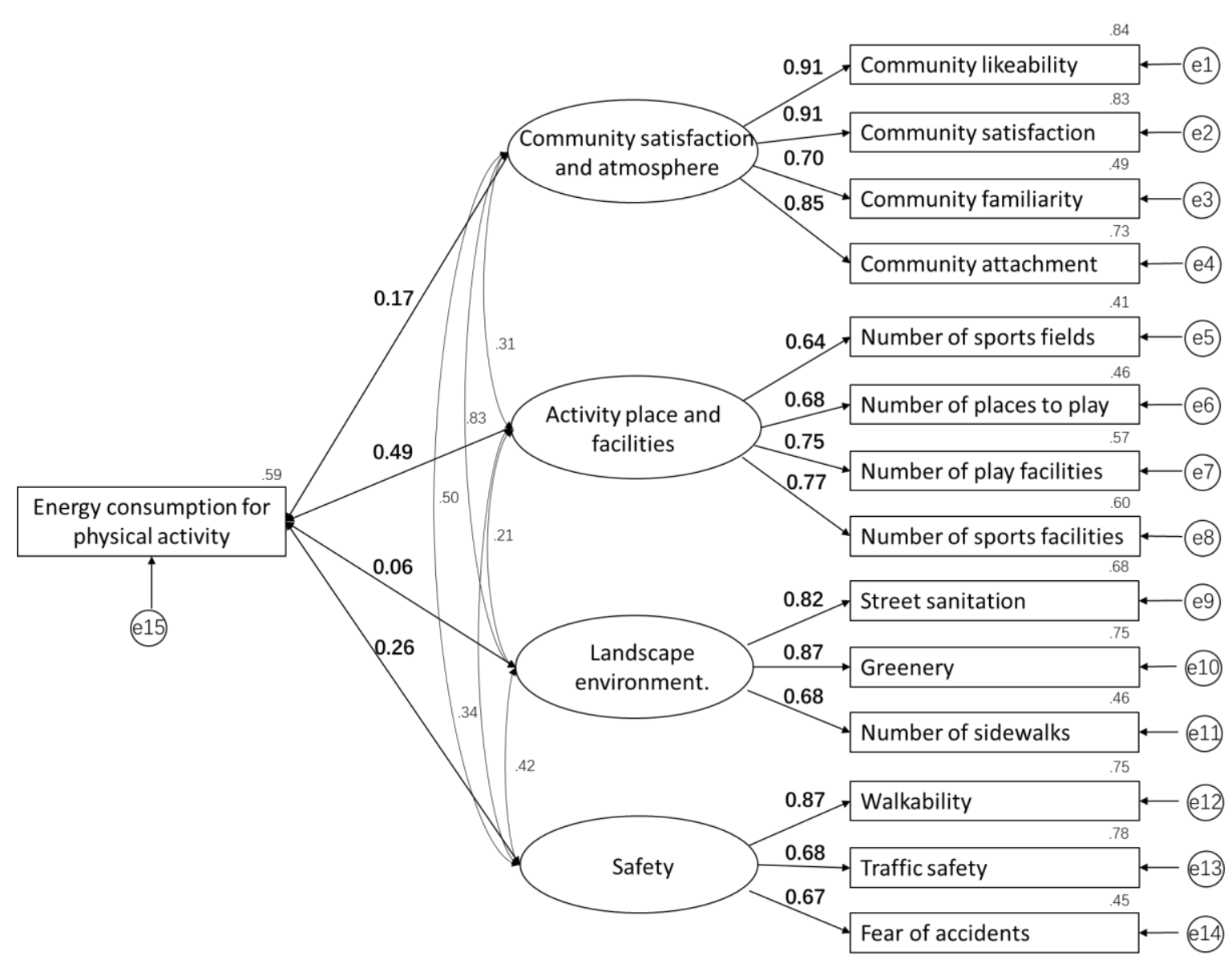

Figure 2. Influence pathway results for the parental perceptions dimension

Table 3. Influence coefficients of parental perceptions dimensions

\begin{tabular}{lcccc}
\hline \multicolumn{1}{c}{ Path } & Standardized coefficient & S.E. & C.R. & P \\
\hline $\begin{array}{l}\text { Energy consumption <--- Community } \\
\text { satisfaction and atmosphere }\end{array}$ & 0.174 & 57.313 & 3.219 & 0.001 \\
$\begin{array}{l}\text { Energy consumption <--- Activity place } \\
\text { and facilities }\end{array}$ & 0.491 & 81.228 & 14.533 & $<0.001$ \\
$\begin{array}{l}\text { Energy consumption <--- Landscape } \\
\text { environment }\end{array}$ & 0.064 & 46.212 & 2.17 & 0.03 \\
Energy consumption <--- Safety & 0.256 & 58.536 & 4.814 & $<0.001$ \\
\hline
\end{tabular}

Figure 3 shows the effect of parental perceived environmental characteristics as a whole on the physical activity levels of children. The model parameter indicators CMIN/DF, GFI, AGFI, CFI, and RMSEA were 4.280 (>3), 0.949 (>0.90), 0.928 (>0.90), 0.966 (>0.90), and 0.060 (<0.08 reasonable) in that order, which all met the appropriate criteria, indicating that the model was acceptable, its fit was good, and its structure was statistical significance. The results showed that the total effect of parental environmental perceptions characteristics on children's physical activity levels had a significant $p$-value $(<0.001)$ and a C.R. value of 3.219 (greater than 1.96), indicating that the effect was significant. The standardized coefficient for the total effect of parental environmental perceptions characteristics on children's physical activity levels was 0.638 . 


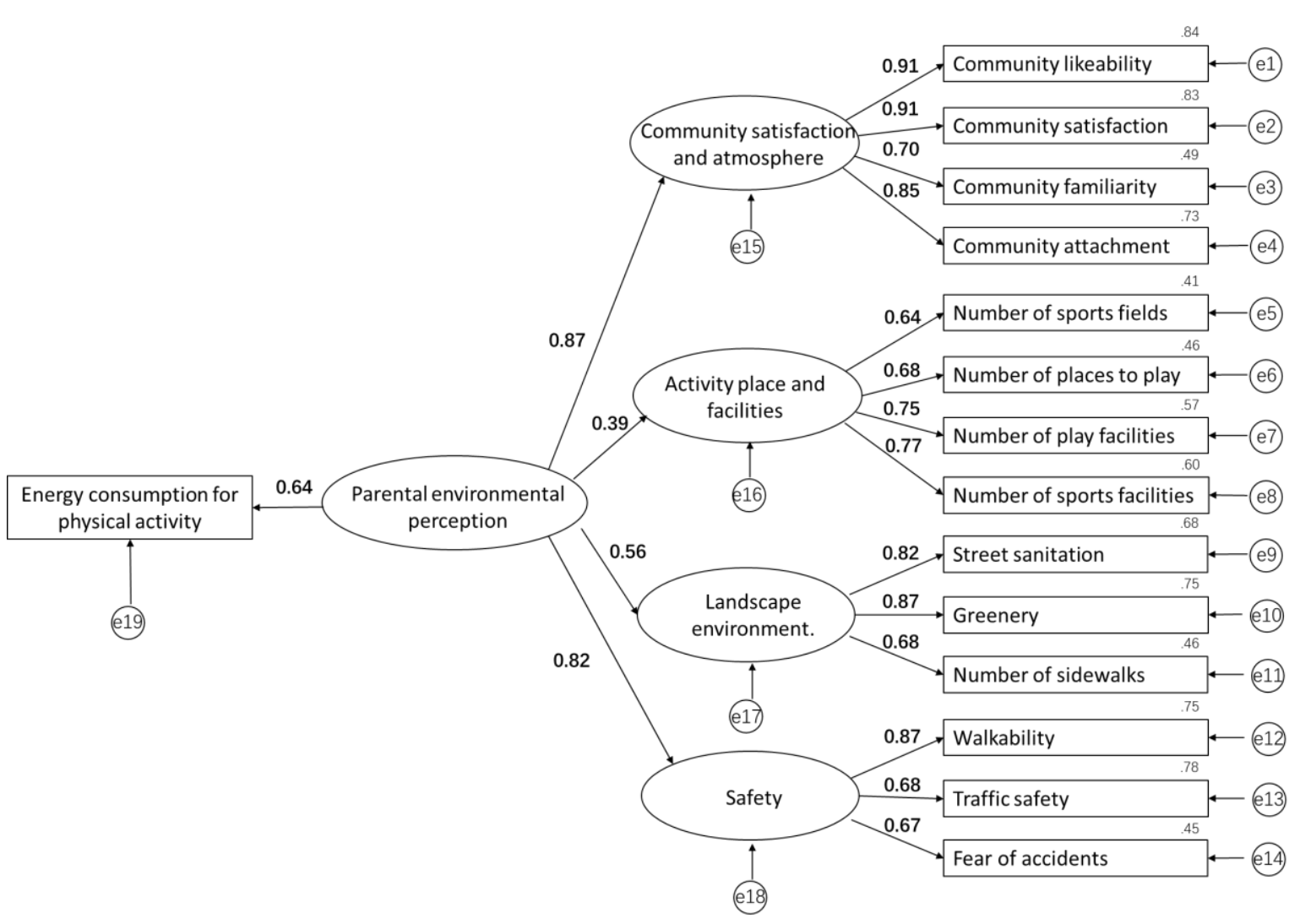

Figure 3. Total effect of parents' environmental perceptions.

\subsection{The effects of children's perceptions}

Table 4 shows the six specific indicators perceived by children have significant effects on children's physical activity levels (Sig.<0.05). The children's perceived environmental characteristics had the following results on children's physical activity levels in order of magnitude: numbers of play facilities, numbers of interesting things, sense of attachment, numbers of natural scenes, numbers of places to play, sense of security.

Table 4. Results of the effects of children's environmental perceptions factors

\begin{tabular}{lcccc}
\hline & $\begin{array}{c}\text { Non-standardized } \\
\text { coefficient }\end{array}$ & $\begin{array}{c}\text { Standardized } \\
\text { coefficient }\end{array}$ & $\mathrm{t}$ & Sig \\
\hline Sense of attachment & 167.533 & 0.124 & 3.508 & 0.000 \\
Sense of security & 122.793 & 0.095 & 2.708 & 0.007 \\
Number of places to play & 109.081 & 0.096 & 2.031 & 0.043 \\
Number of play facilities & 290.217 & 0.253 & 5.419 & 0.000 \\
Number of natural scenes & 124.636 & 0.112 & 3.301 & 0.001 \\
Number of interesting things & 156.307 & 0.131 & 3.610 & 0.000 \\
\hline
\end{tabular}

Notes: $R=0.624, R^{2}=0.389$, adjust $R^{2}=0.385$

The effect of children's perceived environmental characteristics as a whole on children's physical activity levels is shown in Figure 4. M.I. was used to judge the model fit and to make corrections. The model parameters CMIN/DF, GFI, AGFI, CFI, and RMSEA indicators were $4.791(>3), 0.985(>0.90), 0.961$ (>0.90), 0.987 (>0.90), and 0.064 (<0.08 reasonable), in that order, which all met the appropriate criteria, indicating that the model fit was good and its structure was statistically significant. The results showed that the total effect of children's environmental perceptions characteristics on children's physical activity 
levels was significant at $P<0.001$. The C.R. value was 13.604 (greater than 1.96 ), indicating that the effect was significant.

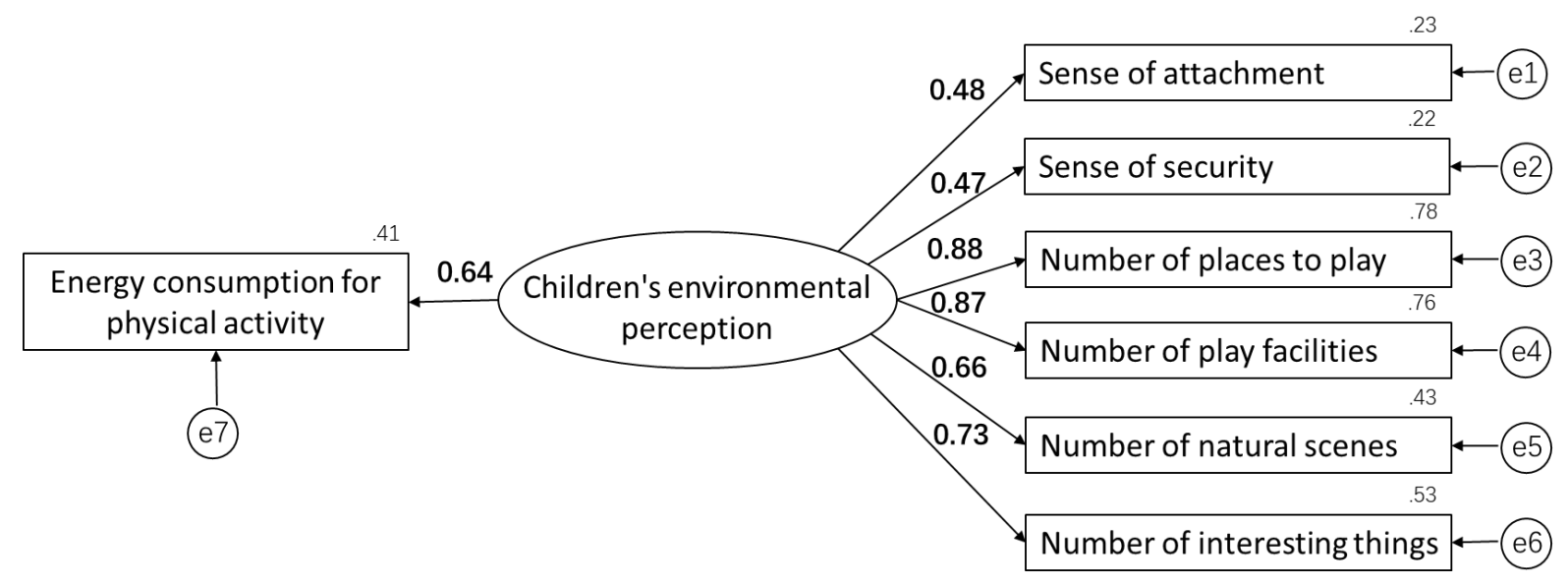

Figure 4. Total effect of children's environmental perceptions

\section{Discussion}

The study results showed that the parental perceptions of environmental characteristics category factors on children's physical activity levels in order of magnitude were: activity place and facilities, safety, community satisfaction and atmosphere, and landscape environment. Parents' perceived number of sports fields, number of places to play, number of play facilities, number of sports facilities, walkability, traffic safety, and community attachment had significant effects on children's physical activity levels. Children's perceived number of play facilities, number of interesting things, sense of attachment, number of natural scenes, number of places to play, and sense of security had significant effects on children's physical activity levels.

The findings are consistent with many studies in which parents' and children's perceived community activity places and facilities were the most influential factors on children's physical activity levels(Babey et al.,2008;Grow et al.,2008;Sallis et al.,2012;Tucker et al.,2009;Veugelers et al.,2008). For example, in a four-year study of children's body fat and physical activity, parental perceptions of the accessibility of sports and activity facilities, such as soccer fields, basketball courts, swimming pools, and corresponding locker rooms, and lighting, were found to be highly correlated with children's physical activity levels and could even be used to predict children's body fat percentage(Horodyska et al.,2018).

In addition, the study found an interesting finding regarding the effect of community safety on children's physical activity. There was a significant difference in the impact of parents' and children's perceived safety on children's physical activity. The effect of parents' perceived safety characteristics on children's physical activity levels ranked second. In contrast, the impact of children's perceptions of safety on children's physical activity levels ranked last in the list of observed indicators. The relationship between community safety and children's physical activity may not be significant, as shown in the results of many studies on the effects of the environment on children's physical activity. For example, a study of preschool children in the United States showed that parental perceptions of neighborhood safety affected times children spent watching electronic screens, instead of their outdoor activity(Burdette and Whitaker,2005). However, other studies provide strong support for the existence of a meaningful relationship between parental perceptions of safety and children's physical activity levels(Bringolf-Isler et al.,2008; Bringolf-Isler et al.,2010). The finding reahch no consensus in the current study and deserved the attention of subsequent studies. 


\section{Conclusion}

The findings suggest that both parents' and children's perceptions of the community environment are factors that influence children's physical activity. In contrast, the total effect of parental environmental perceptions and child environmental perceptions characteristics on children's physical activity levels was essentially the same. There was variability in the degree of influence of specific perceptual factors. Still, parents' and children's perceived characteristics of community activity playgrounds and facilities greatly influenced children's physical activity levels.

The strength of this study is that it examines parental perceptions influence on children's physical activity levels while also consider children's perceptions. Comparing the relationship between the two perceptions clarified the differences in the impact of parental and children's perceptions on children's physical activity, providing a reasonable basis for future research. However, this study also has apparent limitations. The various perceptual factors affecting adolescents' outdoor play covered in this paper may be incomplete, especially in that only six factors were selected for the child perceptual factors. Furthermore, estimating the duration of children's physical activity based on intermediate intervals of time interval data in a way that would be considered an approximation of the actual term is less accurate than the duration of physical activity monitoring with a wearable device.

\section{Acknowledgments and research funding.}

The National Nature Science Foundation of China (No. 51878204)

This research was also supported by Tsinghua Urban Health Index (TUHI) Program funded by Vanke School of Public Health, Tsinghua University (NO.20219990036)

\section{References}

Ainsworth, B.E., Haskell, W.L., Whitt, M.C., Irwin, M.L., Swartz, A.M., Strath, S.J., O’Brien, W.L., Bassett, D.R., Schmitz, K.H., Emplaincourt, P.O., Jacobs, D.R., and Leon, A.S. (2000) 'Compendium of Physical Activities: an update of activity codes and MET intensities', Medicine and Science in Sports and Exercise, 32(9), pS498-S516.

Babey, S. H., Hastert, T. A., Yu, H., and Brown, E. R. (2008). ‘Physical Activity Among Adolescents. When Do Parks Matter?', American Journal of Preventive Medicine, 34(4), 345-348.

Bringolf-Isler, B., Grize, L., Mäder, U., Ruch, N., Sennhauser, F. H., and Braun-Fahrländer, C. (2008). 'Personal and environmental factors associated with active commuting to school in Switzerland', Preventive Medicine, 46(1), 67-73.

Bringolf-Isler, B., Grize, L., Mäder, U., Ruch, N., Sennhauser, F. H., and Braun-Fahrländer, C. (2010). 'Built environment, parents' perceptions, and children's vigorous outdoor play', Preventive Medicine, 50(5-6), 251-256.

Burdette, H., and Whitaker, R. (2005). 'A national study of neighborhood safety, outdoor play, television viewing, and obesity in preschool children', Pediatrics, 116, 657-662.

Carroll-Scott, A., Gilstad-Hayden, K., Rosenthal, L., Peters, S. M., McCaslin, C., Joyce, R., and Ickovics, J. R. (2013). 'Disentangling neighborhood contextual associations with child body mass index, diet, and physical activity: The role of built, socioeconomic, and social environments', Social Science and Medicine, 95, 106-114. 
Carson, V., Kuhle, S., Spence, J. C., and Veugelers, P. J. (2010). 'Parents' perceptions of neighbourhood environment as a determinant of screen time, physical activity and active transport', Canadian Journal of Public Health, 101(2), 124-127.

Davison, K. K., and Lawson, C. T. (2006). 'Do attributes in the physical environment influence children's physical activity? A review of the literature', International Journal of Behavioral Nutrition and Physical Activity, 3(1), 19.

Ginsburg, K. R., Shifrin, D. L., Broughton, D. D., Dreyer, B. P., Milteer, R. M., Mulligan, D. A., ... Smith, K. (2007). 'The importance of play in promoting healthy child development and maintaining strong parentchild bonds', Pediatrics, 119(1), 182-191.

Gouteux, S., and Spelke, E. S. (2001). 'Children's use of geometry and landmarks to reorient in an open space', Cognition, 81(2), 119-148.

Grow, H. M., Saelens, B. E., Kerr, J., Durant, N. H., Norman, G. J., and Sallis, J. F. (2008). 'Where are youth active? Roles of proximity, active transport, and built environment', Medicine and Science in Sports and Exercise, 40(12), 2071-2079.

Horodyska, K., Boberska, M., Knoll, N., Scholz, U., Radtke, T., Liszewska, N., and Luszczynska, A. (2018). 'What matters, parental or child perceptions of physical activity facilities? A prospective parent-child study explaining physical activity and body fat among children', Psychology of Sport and Exercise, 34, 3946.

Jones, A.P., Coombes, E.G., Griffin, S.J., and van Sluijs, E.M.F. (2009). 'Environmental supportiveness for physical activity in English schoolchildren: A study using Global Positioning Systems', International Journal of Behavioral Nutrition and Physical Activity, 6(1),42.

Roberts, J. D., Knight, B., Ray, R., and Saelens, B. E. (2016). 'Parental perceived built environment measures and active play in Washington DC metropolitan children', Preventive Medicine Reports, 3, 373378.

Roemmich, J. N., Epstein, L. H., Raja, S., Yin, L., Robinson, J., and Winiewicz, D. (2006). 'Association of access to parks and recreational facilities with the physical activity of young children', Preventive Medicine, 43(6), 437-441.

Ryu, S., Frith, E., Pedisic, Z., Kang, M., and Loprinzi, P. D. (2019). 'Secular trends in the association between obesity and hypertension among adults in the United States, 1999-2014', European Journal of Internal Medicine, 62, 37-42.

Sallis, J. F., Floyd, M. F., Rodríguez, D. A., and Saelens, B. E. (2012). 'Role of built environments in physical activity, obesity, and cardiovascular disease', Circulation, 125(5), 729-737.

Sithole, F., Veugelers, P. (2008). 'Differences between responses of children and parents in population surveys on children's physical and sedentary activities', Health Reports,19,19-24.

Tappe, K. A., Glanz, K., Sallis, J. F., Zhou, C., and Saelens, B. E. (2013). 'Children's physical activity and parents' perceptions of the neighborhood environment: Neighborhood impact on kids study', International Journal of Behavioral Nutrition and Physical Activity, 10.

Timperio, A., Crawford D., Telford A., and Salmon J. (2004) 'Perceptions about the local neighborhood and walking and cycling among children', Preventive Medicine, 38(1), p39-47.

Trapp, G. S. A., Giles-Corti, B., Christian, H. E., Bulsara, M., Timperio, A. F., McCormack, G. R., and Villaneuva, K. P. (2012). 'Increasing children's physical activity: Individual, social, and environmental factors associated with walking to and from school', Health Education and Behavior, 39(2), 172-182. 
Tucker, P., Irwin, J. D., Gilliland, J., He, M., Larsen, K., and Hess, P. (2009). 'Environmental influences on physical activity levels in youth', Health and Place, 15(1), 357-363.

Veugelers, P., Sithole, F., Zhang, S., and Muhajarine, N. (2008). 'Neighborhood characteristics in relation to diet, physical activity and overweight of Canadian children', International Journal of Pediatric Obesity, 3(3), 152-159.

Ward, Z. J., Long, M. W., Resch, S. C., Giles, C. M., Cradock, A. L., and Gortmaker, S. L. (2017). 'Simulation of Growth Trajectories of Childhood Obesity into Adulthood', New England Journal of Medicine, 377(22), 2145-2153.

Weaver, R. G., Brazendale, K., Hunt, E., Sarzynski, M. A., Beets, M. W., and White, K. (2019). 'Disparities in childhood overweight and obesity by income in the United States: an epidemiological examination using three nationally representative datasets', International Journal of Obesity, 43(6), 1210-1222.

Weir, L. A., Etelson, D., and Brand, D. A. (2006). 'Parents' perceptions of neighborhood safety and children's physical activity', Preventive Medicine, 43(3), 212-217.

Yamashita, S. (2002). 'Perceptions and evaluation of water in landscape: Use of Photo-Projective Method to compare child and adult residents' perceptions of a Japanese river environment', Landscape and Urban Planning, 62(1), 3-17. 